\title{
Flipped classrooms for remote teaching during the COVID-19 pandemic
}

\author{
Marcella Veldthuis \\ The Hague University of \\ Applied Sciences \\ Zoetermeer, Netherlands \\ M.Veldthuis@HHS.NL
}

\author{
Hani Alers \\ The Hague University of \\ Applied Sciences \\ Zoetermeer, Netherlands \\ HAL@HHS.NL
}

\author{
Aleksandra Malinowska \\ University of California, \\ Santa Barbara \\ California, USA \\ Amalinowska@ucsb.edu
}

\author{
Xiao Peng \\ The Hague University of \\ Applied Sciences The \\ Hague, Netherlands \\ X.Peng@HHS.NL
}

\begin{abstract}
COVID-19 inspired universities worldwide to re-evaluate and adjust the ways in which they teach. This article describes how a ten week research course was taught during the pandemic. Since the course already utilized a flipped classroom format, it was possible to give the course entirely online with minimal adjustments. Student grades, questionnaires and video viewing statistics were used to evaluate the new approach. Results show that the course performed similarly to how it did before the pandemic. Students even reported a higher level of satisfaction with the course when given remotely. The new approach has not resulted in a significant difference in grades.
\end{abstract}

\section{ACM Reference Format:}

Marcella Veldthuis, Hani Alers, Aleksandra Malinowska, and Xiao Peng. 2020. Flipped classrooms for remote teaching during the COVID-19 pandemic. In the $9^{\text {th }}$ Computer Science Education Research Conference (CSERC '20), October 19-20, 2020, Leiden, Netherlands. ACM, New York, NY, USA, 2 pages. https://doi.org/10.1145/3442481.3442512

\section{Introduction}

Forms of remote, computer aided learning, have been around as early as the late 1980s [1, 2]. While most institutions of higher education, and some primary and secondary schools, have implemented forms of online instruction, these have been limited to tools such as Canvas and Blackboard. With the COVID-19 pandemic, institutions of education were unexpectedly forced to implement emergency remote learning strategies that were sudden attempts to turn classroom courses into remote learning structures [3].

Remote learning practices in the time of COVID-19, have become an essential tool to continue the learning process. Still, the remote learning process has also shown to have advantages over traditional methods, not only providing access to those who may not be able to access in-person higher education, but also providing “...clear pedagogical advantages over traditional education” [4]. A semisynchronous teaching format allows students to employ just-intime-learning and mastery-based-progression.

Permission to make digital or hard copies of all or part of this work for personal or classroom use is granted without fee provided that copies are not made or distributed for profit or commercial advantage and that copies bear this notice and the full citation on the first page. Copyrights for components of this work owned by others than ACM must be honored. Abstracting with credit is permitted. To copy otherwise, or republish, to post on servers or to redistribute to lists, requires prior specific permission and/or a fee. Request permissions from Permissions@acm.org. CSERC '20, October 19-20, 2020, Leiden, Netherlands

(C) 2020 Association for Computing Machinery.

ACM ISBN 978-1-4503-8872-6/20/10 ..\$15.00

https://doi.org/10.1145/3442481.3442512
Some adolescents may find regulating their behavior difficult based on long-term abstract goals, struggling with skills such as planning, anticipating, prioritizing and focus $[5,6]$. Semi-synchronous learning can help students develop planning skills.

This article discusses the outcomes from a research course held for information and communication technology (ICT) students at The Hague University of Applied Sciences (THUAS). Between 20142019, the course utilized a classroom-only model. It then evolved to a flipped classroom approach in 2019 , and in 2020 , due to COVID-19, changed to a fully remote flipped classroom.

\section{Methodology}

\subsection{Course modules}

The course has two parts: research theory which is based on the book "Research. This Is It!" [8]. The theory of the course is explained in 19 short videos [9]. Three interactive workshops are given during the course to check if students understand the theory. The workshops use a Kahoot which allows lecturers to present questions and students answer using their mobile phones. Students can choose a topic from a list of research challenges to work on. These challenges are coupled to one of the research groups and meet with their research coach and the client to check whether they are conducting the research appropriately and whether their work is on track. Grades are awarded per group based on the quality of the research and the report.

\subsection{Changes introduced for remote teaching}

To simplify the setup of the course and streamline meetings and information gathering, the roles of clients and coach were consolidated in the 2020 (remote teaching) run. The students were scheduled to have weekly online meetings with their coach and

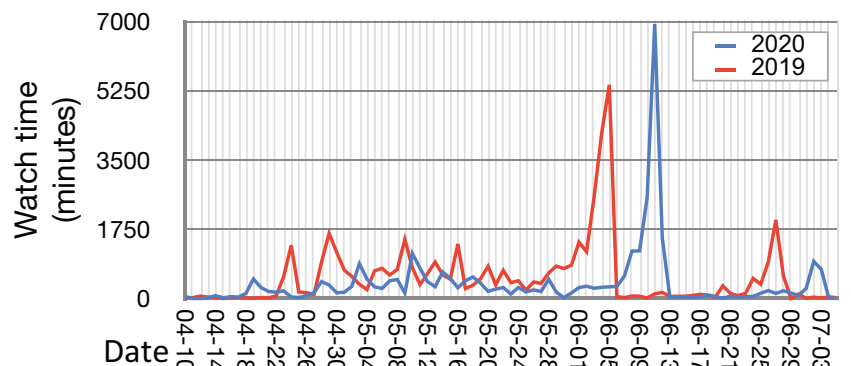

Date $\frac{1}{\circ} \frac{\dot{\Delta}}{\infty}$ N

Figure 1. The total course videos watch time in $\mathbf{2 0 2 0}$ and 2019. The big spike in both years corresponds to the date of the theoretical exam. The exam came a week later in $\mathbf{2 0 2 0}$ 
I prefer this flipped classroom format to traditional lecture based format

When I got stuck with the research the videos helped me figure out how to proceed

The videos helped me in planing how to do the research project

I found the Research-Theory course format (videos + interactive lectures) to be enjoyable

I know more about research after taking the Research-Theory course

I am more interested in research after taking the Research-Theory course

I found this block too easy

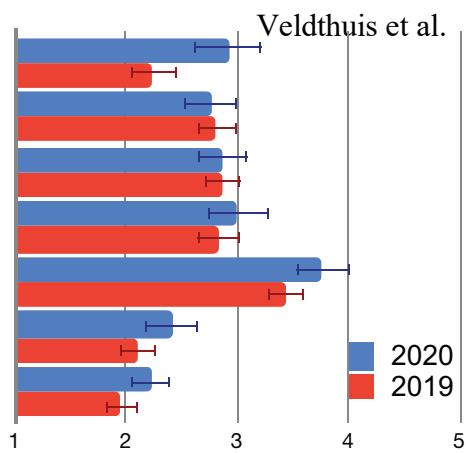

Figure 2. Feedback survey from students on a scale of 1 (disagree) to 5 (agree). Year 2019 and 2020. The error bars (in all figures) represent the standard error of the mean.

client. The three interactive workshops were switched to an online version. Exam is also switched to online. All theoretical knowledge was covered by a few questions that students answered in a short essay format. having four different versions of the exam assigned randomly to the students, performing a fraud check on submitted essays to check for copied content.

\section{Results}

Since the course has been the focus of active research, it is possible to compare data collected in 2020 while the course was given remotely to similar data collected in 2019, the year before. Figure 1 shows the viewing statistics of the 19 videos explaining the course theory. The lines represent total viewing time in minutes for all videos. Individual views were also collected and show a similar trend to that in Figure 1. There is a clear spike in viewing time in both years which immediately precedes the written exam. There is a smaller spike three weeks later which precedes the retake of the written exam. Please note that the exam and the retake came a week later in 2020 than in 2019.

Figure 2 shows the student feedback collected at the end of the course for each year. The students were asked to read statements and rate them on a Likert scale from 1 (labeled as disagree) to 5 (labeled as agree). An independent sample t-test was conducted to compare the results of 2019 and 2020 for each question in Figure 2. There was no significant difference detected between the answers of one year to the other.

Figure 3 shows the student's overall assessment of the course on a scale of 0 to 10 . The error bars again represent the standard error of the mean. This time, the independent sample $\mathrm{T}$ test showed a significant difference in the scores for $2019(\mathrm{M}=3.46, \mathrm{SD}=2.38)$ and $2020(\mathrm{M}=4.88, \mathrm{SD}=2.55)$; with $\mathrm{t}(72)=2.4, \mathrm{p}=0.019$. This means

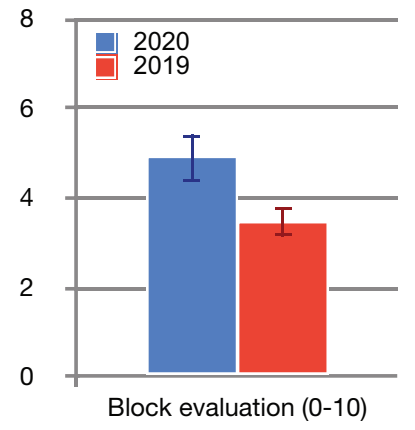

Figure 3. Overall student evaluation that the students were significantly more positive about the course in 2020 than in 2019.

Finally, Figure 4 shows the grades students scored for the theoretical exam. This course is considered to be one of the more challenging courses and this is reflected in the low grades (passing grade is 5.5). An independent sample t-test showed no significant difference between the scores of the two years. This means that despite the change in the course and exam format, the student performed similarly to the previous year.

\section{Conclusion}

This study suggests that flipped classroom methods may provide robust teaching models in a crisis format, such as that with the COVID-19 pandemic. Preparing high quality video lecture materials as well as collaborative spaces for discussion and student engagement can be a successful formula to meet the needs of remote learning models.

\section{References}

[1] Mason, R., \& Kaye, A. Eds. (1989). Mindweave: Computers, Communication and Distance Education. Oxford: Pergamon.

[2] Riel, M. \& Levin, J. (1990). Building electronic communities: successes and failures in computer networking. Instructional Sci. 19, 145-169.

[3] Hodges, C., Moore, S., Lockee, B., Trust, T., \& Bond, A. (2020). The difference between emergency remote teaching and online learning. Educause Review, 27.

[4] Caplan, B. (2018). The Case against Education: Why the Education System is a Waste of Time and Money. Princeton, NJ: Princeton University Press.

[5] Nelis, H. \& Van Sark, Y. (2010) Puberbrein binnenstebuiten. Wat beweegt jongeren van 10 tot 25 jaar? (7e, herziene en uitgebreide druk). Utrecht/Antwerpen, Kosmos Uitgevers B.V.

[6] Slot, W., \& Van Aken, M. (2013). Psychologie van de adolescentie. Basisboek. Amersfoort: ThiemeMeulenhoff.

[7] Alers, H., Veldthuis, M., Malinowska, A., \& Cocx, T. (2019, November). A Flipped Classroom Experiment: The implementation of Semi-Synchronous Learning. In Proceedings of the 8th Computer Science Education Research Conference (pp. 118-119).

[8] Baarda, B. (2010). Research. This is it. Noordhoof.

[9] Clark, R. C., \& Lyons, C. (2010). Graphics for learning: Proven guidelines for planning, designing, and evaluating visuals in training materials. John Wiley \& Sons. 